\title{
COMPLEXITY AS THE DEFINING FEATURE OF THE 21ST CENTURY
}

\author{
G. RZEVSKI ${ }^{1,2}$ \\ ${ }^{1}$ The Open University, UK. \\ ${ }^{2}$ Milton Keynes \& Multi-Agent Technology Ltd., UK.
}

\section{ABSTRACT}

The 21 st century is often labelled as the Century of Complexity because complexity of the socio-technological environment in which we live and work has reached the level that no longer can be ignored - complexity affects now all aspects of our lives. The paper defines complexity, identifies its sources and explains the basics of the new science and the art of managing complexity. The importance of complexity is discussed in the context of social, business and engineering systems.

Keywords: adaptation, complexity, managing complexity, multi-agent technology, real-time decision-making, self-organisation.

\section{INTRODUCTION}

Complexity is an inherent property of many systems that constitute the environment in which we live and work, namely, ecological, biological, thermodynamic and social systems (including political, administrative, economic, business and socio-technical systems). Until recently, the levels of complexity of social systems were low and, consequently, complexity was largely ignored. However, with the rapid development of digital technology, the situation has changed, particularly when the Internet transformed the world into a 'global village' and linked regional and national markets into a single 'global market'.

Many researchers have contributed to the understanding of complexity, notably Prigogine [1,2], Kaufman [3], Holland [4] and many others. As always at the onset of a paradigm shift, there are several competing 'schools' of complexity science.

This paper is based on the pioneering work on developing experimental science and the art of managing complexity [5].

\section{WHAT IS COMPLEXITY?}

Complexity is a property of open systems that consist of a large number of diverse, interacting components, often called agents. Complex systems can be distinguished from other systems by the seven features: connectivity, autonomy of agents, emergent behaviour, nonequilibrium, nonlinearity, self-organisation and co-evolution.

Connectivity - Agents are interconnected. Complexity of the system increases with the number of links that connect agents to each other. Complexity also depends on the strengths of links. The weaker the links between agents, the easier is to break them and form new ones, which increases system complexity.

Autonomy of agents - Agents have certain freedom of behaviour (autonomy), which is always limited by norms, rules, regulations and/or laws. The increase in autonomy of agents increases the complexity, and if all constraints on agent behaviour are removed, the system switches from complex to random behaviour. Inversely, if autonomy of agents is reduced (by tightening of laws and regulations), the system complexity will decrease, and in the extreme, the system will become deterministic. Complex systems have no central control. 
Emergent behaviour - Behaviour of complex systems emerges from the interactions of agents and is not predictable, and yet it is not random. Uncertainty about the outcome of agent interactions is always between 0 and 1 .

Nonequilibrium - Complex systems are subjected to perpetual change experienced either as a succession of discrete disruptive events or as a slow, imperceptible drift into failure. Frequency of disruptive events varies with complexity. In systems of high complexity, disruptive events occur so frequently that the system has no time to return to stable equilibrium before the next disruption occurs. When complexity levels are very high, the system is said to be at the edge of chaos because the uncertainty of behaviour is close to 1 .

Nonlinearity - Relations between agents are nonlinear. Nonlinearity may amplify a small, insignificant disruptive event and cause a catastrophic outcome (an extreme event), the property called butterfly effect. Butterfly effect increases with complexity. In complex systems, the outcomes are, as a rule, consequences of numerous interacting causes, and therefore, the cause-effect analysis is inappropriate.

Self-organisation - Complex systems have a propensity to react to disruptive events by autonomously self-organising with the aim of eliminating or, at least, reducing the consequences of disruption, the property called adaptation. Self-organisation may be also caused autonomously by a propensity to improve own performance, the property called creativity or innovation. To initiate and perform adaptive and creative activities, the system must be intelligent. Intelligence, adaptation and creativity are the properties exclusive to complex systems and their levels increase with complexity.

Co-evolution - With time, complex systems co-evolve with their environments. Co-evolution is irreversible.

\section{COMPLEX VERSUS DETERMINISTIC AND RANDOM SYSTEMS}

Let us use uncertainty of behaviour as the demarcation parameter to distinguish complex systems from deterministic and random systems, as shown in Table 1.

The term deterministic implies that uncertainty is equal to 0 , while the term random means that uncertainty is equal to one. Complex systems have uncertainty value between 0 and 1 .

Table 1 highlights the link between complexity and uncertainty of system behaviour: uncertainty is a consequence of complexity and it increases with complexity. Low complexity systems have uncertainty close to 0 and their behaviour differs little from the behaviour of deterministic systems. Highly complex systems with uncertainty close to 1 are at the edge of chaos and their behaviour is characterised by features such as self-organisation, generation of unpredictable extreme events and co-evolution.

Table 1: Complex versus deterministic and random.

\begin{tabular}{lll}
\hline Random & Complex & Deterministic \\
\hline Uncertainty of outcome $=1$ & $1>$ Uncertainty of outcome $>0$ & Uncertainty of outcome $=0$ \\
Components have full & $\begin{array}{l}\text { Components (called agents) have } \\
\text { partial autonomy }\end{array}$ & Components have no autonomy \\
autonomy & $\begin{array}{l}\text { Self-organising } \\
\text { Disorganised }\end{array}$ & Evolving \\
Unpredictable behaviour & Emergent behaviour & Predictable behaviour \\
\hline
\end{tabular}


The distinction between complex and deterministic systems is very important and has philosophical repercussions. For centuries, eminent philosophers and scientists have believed that the world is deterministic - that it behaves in accordance with natural laws in a predictable manner and that any uncertainty of outcomes is a result of our lack of knowledge on how the world works. In other words, for supporters of determinism, the world is complex only for those who do not understand it.

A more plausible alternative view has been put forward recently by Prigogine [1,2]. The world is inherently complex and it evolves with time. Future is not given; it emerges from the interaction of billions of activities performed by constituent agents, including people, animals, plants as well as natural forces such as climate, erosion, volcanic eruptions and solar spots. Only certain limited parts of the world can be represented by deterministic models such as Newton's laws.

\section{CO-EVOLUTION OF SOCIETY AND TECHNOLOGY}

Historically, complexity of social systems increased in steps, driven by the advances in technology, as depicted in Table 2, and at each step, the impact on the way we live and work was dramatic.

During the transition between agricultural and industrial societies, rapid migration of the population from the countryside to the cities, to take advantage of new employment opportunities, increased the social connectivity in the increasingly dense cities and, as a result, raised the level of social complexity. The massive movement of population caused well-documented disturbances as a rigid, traditional social order based on land ownership was replaced by a chaotic transition, which then settled into a new social order based on ownership of capital.

The current transition from industrial to information society, which began after the end of the World War 2 with the invention of computers, is particularly notorious by the very steep increase in social complexity caused by the rapid spread of digital technology, which offers unparalleled social connectivity (social density), but this time without any need for the population to move. Now we can form communities of interests across the globe. Distances do not matter anymore.

Thanks to digital technology, participants in the information society interact faster, more frequently and with greater number of correspondents than ever before. In the year 2013, approximately 3 billion people have used the Internet, which is more than $40 \%$ of the total number of people on the planet and, according to the Time news feed, up to 6 billion people had access to a mobile phone. This is an astonishing increase in connectivity causing an accelerated growth of complexity.

As connectivity has increased, we have experienced a very important shift from nation-centred industrial markets to the global economy dominated by knowledge-based services. In the industrial economy, money could buy any knowledge needed for business. In the knowledge economy, the knowledge of how to solve complex problems can attract investments that are required to start and sustain an economic activity. Pioneers of the knowledge economy, founders of knowledge-based

Table 2: Co-evolution of technology and society.

\begin{tabular}{lllll}
\hline Social stages & Key resources & Distribution & Scope & Success factors \\
\hline $\begin{array}{l}\text { Information society supported by } \\
\text { digital technology }\end{array}$ & Knowledge & $\begin{array}{l}\text { Digital } \\
\text { networks }\end{array}$ & Global & Adaptability \\
$\begin{array}{l}\text { Industrial society supported by mass } \\
\text { production technology }\end{array}$ & Capital & $\begin{array}{l}\text { Railways } \\
\text { motorways }\end{array}$ & National & Economy of \\
$\begin{array}{l}\text { Agricultural society supported by } \\
\text { manual labour }\end{array}$ & Land & Local roads & Local & Hard work \\
\hline
\end{tabular}




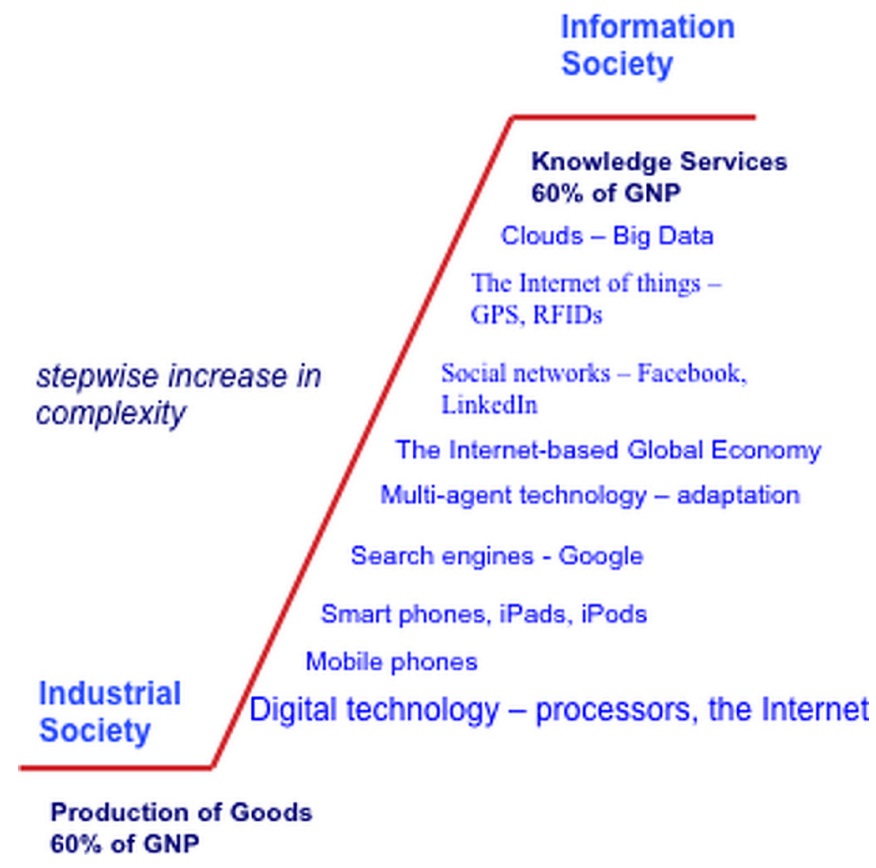

Figure 1: Steep increase in complexity of social systems caused by rapid penetration of digital technology.

companies such as Apple, Google, Amazon, Microsoft and Facebook, are the new economic elite. The shift of mass manufacturing from the developed to the developing countries is a part and parcel of globalisation. However, the replacement of mass manufacturing by knowledge-based services as the main wealth creation activity occurred only in the countries where there exists expertise in advanced IT and a large number of high-class knowledge workers: researchers, designers and decision-makers in financial services, IT, engineering, consulting, construction, architecture, entertainment, media, etc.

Big monolithic corporations are the product of the industrial economy, which was characterised by stable markets generating steady demands for identical, mass produced goods. Big corporations were designed to be rigid and permanent and they thrived in the era when the Economy of Scale was the key success factor. The new complex global market is the enemy of anything big and rigid. The new critical success factor is adaptability, and therefore, we can safely assume that large corporations will not have an easy future, with the exception of those that manufacture uniform products exemplified by nappies or nuts and bolts.

However, big corporations have a remarkable ability to survive and many will re-invent themselves and continue in a more appropriate format. The organisational structure that is the most suitable for delivering to perpetually changing markets is a network of self-contained production units, each having a unique expertise (knowledge resource), often referred to as Virtual or Digital Enterprise.

The concentration of data on financial transactions, on communication with friends and business associates, and on individual mobility in huge 'clouds', by organisations such as Google, raises important questions on individual privacy. It is only natural to expect that those who have knowledge 


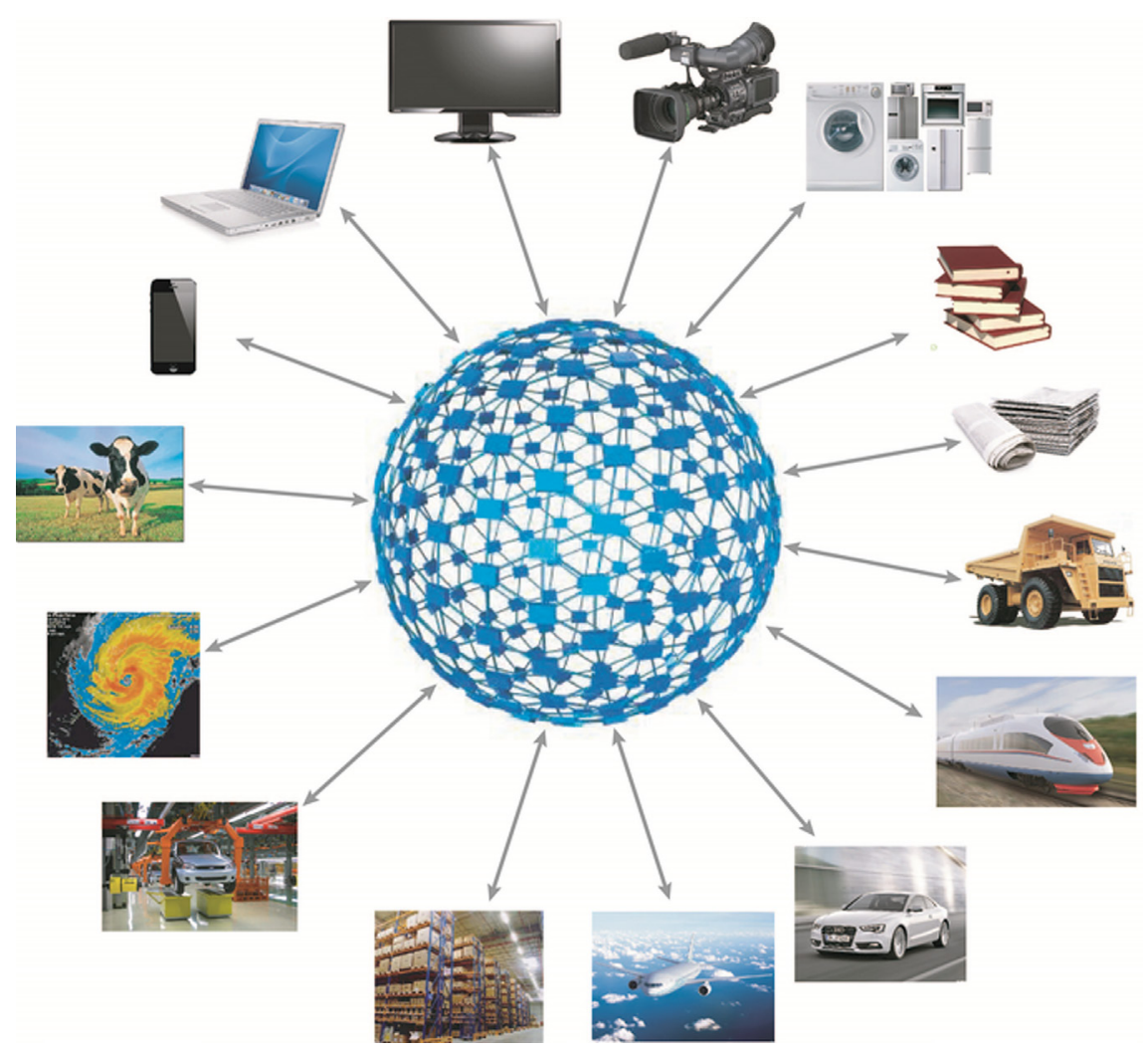

Figure 2: The global network.

about us will try to use this knowledge to manipulate our behaviour. Knowledge is power. Who will exercise this power acquired by accumulation of digital data about every aspect of our life? Will a private company (possibly in collusion with a government intelligence service) manage to acquire sufficient quantity of data to establish monopoly of knowledge? Or, can we expect that the process of natural selection will ensure the distribution of knowledge? It is safe to be an optimist. Evolution favours complexity, which implies diversity and distributed decision-making rather than centralisation, although the process is slow and by no means smooth.

Figure 2 shows the emerging global network; as all texts, images and videos/films are digitised (the Internet of Documents), more and more people are connecting through mobile devices and the Internet (the Internet of People) and objects of practical importance to humans are furnished with electronic tags, enabling them to communicate with each other bypassing their users (the Internet of Things).

\section{PROSPERING IN A COMPLEX ENVIRONMENT}

We have been brought up in Newtonian deterministic tradition and feel comfortable in well-defined stable situations. We crave for simplicity and predictability.

As it happens, complexity of the environment in which we live and work is relentlessly increasing and it now intrudes into every aspect of our existence. The increase in complexity is disruptive - by making our well-established systems and processes ineffective, it forces paradigm shifts opening up 
opportunities for creating a new order in society, politics, law, policy, education, research, business, design, engineering and elsewhere.

To take advantage of new opportunities, it is helpful for individuals and organisations to develop the so-called 'complexity mindset', which, in a nutshell, consists of beliefs, principles and methods that define the relation between an individual or an organisation and the ever-changing world with which they have to co-evolve.

\section{MANAGING COMPLEXITY}

A new scientific discipline entitled 'managing complexity' contains a growing collection of concepts, principles and methods for successfully living and working with complexity [5].

There are two aspects of managing complexity:

- Coping with external complexity (complexity of the environment) and

- Creating and tuning internal complexity

Some of the key concepts and principles are briefly outlined below.

\subsection{Coping with external complexity}

By definition, we do not have control over our environment, and therefore, we cannot control its complexity. The best strategy for coping with external complexity is to develop the capacity for adaptation, which implies designing complexity into our processes and structures because only complex systems can self-organise and thus adapt.

To be adaptive means to be able to achieve desired goals under conditions of frequent occurrence of unpredictable disruptive events. Adaptability is achieved by rescheduling affected resources to eliminate or, at least, to reduce consequences of a disruptive event before the next one occurs.

Key requirements for adaptability are:

- Distributed rather than centralised decision-making

- A sufficient redundancy of resources to enable unpredictable rescheduling

- Availability of technology capable of

- Early detection of disruptive events

- Real-time rescheduling of affected resources

- Continuous improvement of performance to avoid a drift into failure

\subsection{Tuning internal complexity}

The level of complexity of systems/organisations, which we design or control, can be adjusted by changing

- Agent autonomy and

- Agent connectivity

This is largely a trial-and-error process, informed by experience in designing and managing large-scale complex adaptive systems, as described in some detail in [5]. 


\section{COMPLEXITY AND SOCIETY}

For the purposes of this paper, I shall assume that any system in which large numbers of agents are people is a social system. Then we can postulate that any social system in which members (a) have a high level of autonomy, (b) are able to communicate with many other members and (c) can change established communication links easily is a complex social system. Such a system is adaptive and, therefore, resilient to disruptions and attacks; it co-evolves with its environment, and therefore, it never becomes obsolete [6].

And yet, we tend to design organisations that are pseudo-deterministic and controlled by elaborate hierarchical management structures, rather than self-organising. To achieve this, we constrain human natural intelligence and creativity.

\section{COMPLEXITY AND BUSINESS}

A business is of course a social system. It is necessary though to single out peculiarities of this class of social systems because businesses create wealth [5].

A great majority of businesses today participate in the Internet-based global market. Suppliers, customers, traders, investors, bankers, consultants and middlemen are negotiating, agreeing, modifying or cancelling transactions in unprecedented numbers and with unprecedented speeds. As a consequence, the global market has become volatile and the frequency of disruptive events is such that the market, once disturbed, has no time to return to stable supply/demand equilibrium. Complexity of the global market cannot be reduced or influenced in any way by any business, even by the biggest one. Also, it has to be accepted that the complexity will not go away. In fact, there exists ample evidence that it will increase as more and more people and things connect to the Internet.

Businesses operating under such conditions have considerable difficulty in planning and managing their internal business processes. Traditional decision-making and resource optimisation approaches do not deliver expected results.

Clearly, the solution is to develop capacity for adaptability.

Manufacturing of cars is an instructive example. One of the leading European car manufacturers, for whom I worked as a consultant, still spends a large sum of money on out-of-date production optimisation software that requires $8 \mathrm{~h}$ or so to produce a perfect (deterministic) production schedule, which becomes obsolete a couple of hours after it is implemented because changes to previously agreed orders arrive from dealers approximately one per $2 \mathrm{~h}$. As a result, the company manufactures cars that are not wanted anymore and have to be sold with discount.

A real-time, complex adaptive scheduler, such as one described in [6], would cost less and would be able to re-schedule affected parts of the production plan whenever a request for a change arrives.

\section{COMPLEXITY AND ENGINEERING}

Engineering systems have been always designed to exhibit deterministic behaviour within specified operational range. To achieve this aim, dynamic engineering systems that have a variety of possible behaviours, such as machines, vehicles, aircraft, rockets and robots, had to be provided with a controller, human or automatic, to behave predictably.

In contrast, the behaviour of complex systems is emergent (unpredictable) and these systems have no controllers - they are adaptable - and they self-organise when disturbed to eliminate or, at least, to reduce the consequences of the disturbance. This is precisely why complex engineering systems are valuable when they operate in complex environments where adaptation has an advantage.

Consider an example. The US sent a robot to Mars, which stopped functioning after a few weeks because space dust covered its solar cells. Then UK sent a robot to Mars, which fell into a crevice 


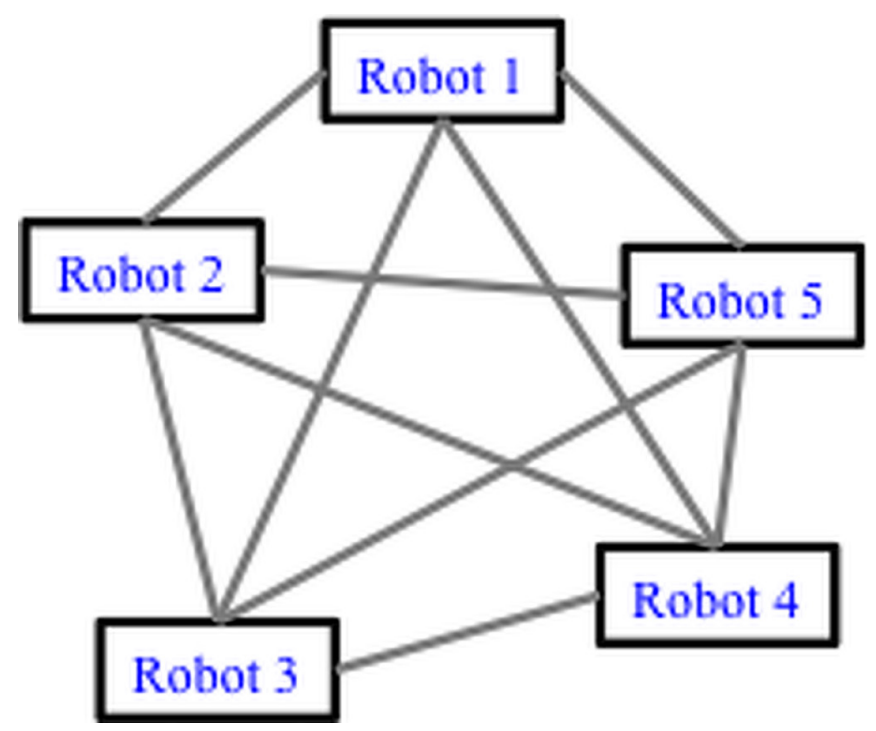

Figure 3: A complex engineering system depicting a family of five robots.

before it could even start to do some useful work. That was a massive waste of resources and time entirely due to outdated thinking of robot designers. A family of five much smaller robots, as shown in Fig. 3 below, would be able to share the workload, clean and maintain each other, and either drag out the unfortunate family member that fell into a crack or abandon it and share its workload among those that survived. That would be a perfect complex adaptive engineering system.

\section{CONCLUSION}

There exists ample evidence that, driven by the rapid development of digital technology, complexity of our socio-economic environment is perpetually increasing and it has by now reached the level that no longer can be ignored.

It is, therefore, of paramount importance for all those who live in the new global village and work in the emerging global market to develop the appropriate complexity mindset, which would enable them to take advantage of fresh opportunities in research and practical applications currently on offer.

\section{REFERENCES}

[1] Prigogine, I., The End of Certainty: Time, Chaos and the new Laws of Nature, Free Press, 1997. ISBN 0-684-83705-6.

[2] Prigogine, I., Is Future Given?, World Scientific Publishing Co., 2003. ISBN 981-238-508-8.

[3] Kaufman, S., At Home In the Universe: The Search for the Laws of Self-Organization and Complexity, Oxford Press. 1995. ISBN 0-19-511130-3.

[4] Holland, J., Emergence: from Chaos to Order, Oxford University Press, ISBN 0-19-850409-8. 1998.

[5] Rzevski, G., Skobelev, P., Managing Complexity, WIT Press, 2014. ISBN 978-1-84564-936-4.

[6] Rzevski, G. Self-Organisation in Social Systems, Ontology of Designing. 4(14), pp. 8-17, 2014. ISSN 2223-9537.

[7] Rzevski, G., Using Complexity Science Framework and Multi-Agent Technology in Design, In Embracing Complexity in Design, eds. K. Alexiou, J. Johnson, T. Zamenopoulos, Routledge, 2010, ISBN 978-0-415-49700-8, pp. 61-72. 